\title{
Artigo: Avaliação e Políticas Públicas em Educação': Fatores determinantes na qualidade e formação de profissionais ${ }^{2}$
}

\author{
José Jairo Vieira - PPGE - UFRJ \\ Marcelo Pereira de Moraes - UFRJ \\ Andréa Lopes da Costa Vieira - PPGMS - UNIRIO
}

Este trabalho visa demonstrar o quanto é importante a avaliação das estratégias, planos e programas implantados no sistema educacional com a finalidade de aperfeiçoar, corrigir, desenvolver, adicionar novas metodologias e tomar decisões. Uma avaliação construtiva proporciona estas oportunidades para desenharmos um sistema público educacional de qualidade, de acordo com nossas demandas e realidades. Discrepâncias são localizadas de maneira bem clara quando verificamos índices estatísticos voltados para termos quantitativos como exemplo Censo relativos ao PROUNI, FUNDEF e PROHACAP, deixando de lado um índice que caminha paralelamente e é imprescindível para a realização e união da eficiência, eficácia e da produtividade: “a qualidade”. Após a iniciação desta pesquisa, já podemos verificar de maneira geral que com as pessoas certas nos lugares certos, bem qualificadas e treinadas, com uma adequação e implantação de políticas públicas voltadas para nossas demandas sem introduzir pacotes internacionais que não condizem com nossa realidade, com um Órgão fiscalizador externo, como exemplo o CGU, efetuando auditorias voltadas para a área da educação, dentro dos prazos necessários, com uma análise curricular mais específica do que generalista da formação de novos profissionais e tendo como base uma Instituição séria e impessoal voltada para o fornecimento na íntegra dos índices estatísticos supervenientes, há uma grande possibilidade de qualificarmos melhor a educação brasileira.

Palavras-chave: Politicas Publicas de Educação, Avaliação de Politicas, Qualidade da Educação, Formação de Professores 
This work aims to demonstrate how important it is to evaluate the strategies, plans and programs implemented in the educational system in order to improve, correct, develop, add new methods and decisions. A constructive evaluation provides these opportunities to draw a quality public education system, according to our demands and realities. Discrepancies are located very clearly when we see statistical indices facing quantitative example Census relating to PROUNI, Fundef PROHACAP and, leaving aside an index that goes hand in hand and is essential for the realization of the unity and efficiency, effectiveness and productivity : " quality ". After initiation of this research, we can verify in general that with the right people in the right places, well qualified and trained, with an adaptation and implementation of public policies for our demands without introducing international packages that do not match our reality with an Organ external watchdog, the example of the CGU, performing audits focused on the area of education, within the time required, with a curriculum analysis more specific than general training of new professionals and based on an institution serious and impersonal toward the delivery in full of statistical indices supervening, there is a great possibility of better

qualify Brazilian education

Keywords : Public Policy Education, Assessment Policies, Quality of Education, Teacher Traini

\section{1 - Introdução}

Este trabalho visa demonstrar o quanto é importante a avaliação das estratégias, planos e programas implantados no sistema educacional com a finalidade de aperfeiçoar, corrigir, desenvolver, adicionar novas metodologias e tomar decisões.

Segundo Ferreira, avaliar significa determinar a valia de algo, atribuir um valor . Já Ala-Harja e Helgason, definem que "o termo compreende a avaliação dos resultados de um programa em relação aos objetivos propostos".

O Comitê de Assistência ao Desenvolvimento da OCDE assinala que o propósito da avaliação é determinar a pertinência e alcance dos objetivos, a eficiência, efetividade, impacto e sustentabilidade do desenvolvimento. A avaliação deve proporcionar informação que seja crível e útil para permitir a incorporação da experiência adquirida no processo de tomada de decisão. A avaliação deve ser vista como um mecanismo de melhoria no 
processo de tomada de decisão, a fim de garantir melhores informações, sobre as quais eles possam fundamentar suas decisões e melhor prestar contas sobre as políticas públicas (AlaHarja e Helgason, 2000).

\section{2 - Referencial teórico, Desenvolvimento e Metodologia}

Observando o processo evolutivo educacional nas Instituições de Ensino Superior, geralmente pode-se verificar um grande volume de informações e diversas disciplinas no histórico dos profissionais formandos de cada especialidade. Fazendo uma pequena análise pessoal sobre o assunto pressupõe-se que o atual formando é conhecedor com uma visão ampla da carreira optada e através desta formação será reconhecido e bem remunerado no mercado de trabalho. No entanto, a qualidade nos serviços tem sido muito questionada por instituições e agências que controlam e gerenciam os direitos dos consumidores. A atual estratégia adotada através de Políticas Públicas implantadas nas IES é a voltada para o desenvolvimento deste modelo de profissionais que atualmente pertence a uma "sociedade do conhecimento" onde a maior preocupação esta em reduzir o insucesso e não desperdiçar os recursos humanos e materiais utilizados. (Política Educacional, 2007)

Analisando o caso através deste pensamento verificamos que existe um interesse político elitizado que direciona qual a estratégia de Políticas Públicas a serem adotadas, ocasionando em uma falsa autonomia do profissional onde seus conhecimentos são noções abrangentes e não especializadas. Com isso, um efeito dominó de ocorrências na qualidade de ensino e na valorização dos profissionais tanto dos prestadores dos serviços, especificamente as IES, como também os formandos.

Os índices estatísticos voltados para a qualidade no ensino baseiam-se em dados de uma pequena área de dispersão onde os dados manipulados são somente de interesse específico de uma elite onde possam satisfazer as expectativas da massa e angariar recursos através de instituições internacionais como a OMC e o FMI.

Respeitando as exigências impostas aos países emergentes através do receituário Neoliberal pelos órgãos internacionais, nas últimas décadas, nosso país investe maciçamente na educação básica aplicando políticas públicas estabelecendo-se limites mínimos de aplicação obrigatória em sua manutenção e desenvolvimento, fixando-se pesadas sanções em caso de descumprimento. Instituiu-se o FUNDEF. Exigiu-se formação superior para docentes atuantes nessa fase da educação. Autorizou-se a utilização de recursos públicos no financiamento de programas destinados à habilitação de professores leigos. Instituiu-se a distribuição de renda às famílias de alunos carentes mediante a 
comprovação de frequência escolar.

Esta pretensão reformista foi alicerçada por diversas políticas públicas cujos resultados, do ponto de vista quantitativo, revelaram-se positivos. A Taxa de Atendimento ao Ensino Fundamental cresceu mais de 17 pontos percentuais no período de 1980 a 2006 e, atualmente, alcança o patamar de $98 \%$. O percentual de professores com formação superior cresceu mais de 30 pontos percentuais no período de 1996 a 2006, resultado que se deve, em parte, aos programas destinados a habilitar professores leigos, consoante previsão contida na LDB e na Lei do FUNDEF. A Taxa de Abandono Escolar foi reduzida em mais de 5 pontos percentuais nesse período, graças ao programa Bolsa Escola/Família, instituído a partir de 2001.

O impacto financeiro produzido por essas ações elevou substancialmente o valor do Custo-Aluno-Ano, que representa o total dos gastos em educação dividido pela quantidade de alunos. Em nível nacional, o valor passou de $\mathrm{R} \$ 1.258,00$, em 2001, para $\mathrm{R} \$ 1.679,00$, em 2006, evidenciando um significativo aumento de recursos financeiros aplicados na educação.

Em termos qualitativos, as expectativas almejadas não foram alcançadas. A repetência escolar, o mais grave problema enfrentado pelas nossas autoridades, ainda está longe de ser resolvida. Estacionada na casa dos 20\%, desde 1998, essa taxa é superior a de países como Ruanda (19\%), Haiti (16\%), Camboja (11\%), e muito além da taxa registrada pelos nossos vizinhos da América do Sul: Chile (4,9\%), Uruguai (9\%) e Argentina (9,5\%).

Do ponto de vista social, a repetência escolar afeta psicologicamente o aluno, passando a carregar o rótulo de repetente durante o ano letivo,isto caso não abandone a escola antes, causa obstáculo impedindo o acesso de novos alunos e dificulta o relacionamento com os professores e os colegas de classe. Do ponto de vista financeiro, estudos revelam que uma taxa de repetência no patamar de $20 \%$ gera mais de 8 bilhões de reais de prejuízos ao ano aos cofres do país.

Das razões atribuídas ao fracasso escolar, tanto de natureza intra quanto extraescola, duas sobressaem com frequência: a) falta de qualificação dos professores; e b) baixo investimento educacional. Malgrado tais conclusões, observa-se que, embora o nível de qualificação de docentes e o volume de recursos aplicados em educação se constituam em fatores positivos no processo ensino/aprendizagem, não se pode garanti-los como determinantes no processo de melhoria da qualidade do ensino.

Em nível nacional, a elevação do montante de valores aplicados no Ensino Fundamental, refletida na majoração do Custo-Aluno-Ano, não foi suficiente para reduzir a 
Taxa de Repetência, que permaneceu na casa de 20\%. Da mesma forma, observou-se que o crescimento da quantidade de professores com formação superior não foi capaz de reduzir a mencionada repetência escolar.

Estudos feitos em Escolas Municipais em Rondônia demonstraram que investimentos através do PROHACAP elevou em 40 pontos percentuais o número de Docentes com formação Superior, enquanto a taxa de repetência dos alunos manteve-se em $20 \%$.

Outro fator analisado foi o Custo-Aluno-Ano que mesmo sendo inferior a média nacional não foi um fator determinante para um alto índice de reprovação. Dos 52 municípios do Estado, 23 obtiveram um rendimento escolar acima da média.

Quanto as políticas públicas voltadas para o acesso ao nível superior, o Governo desenvolveu o programa PROUNI, cujo objetivo principal é oferecer oportunidade de estudos para pessoas com baixo poder aquisitivo, professores da rede pública de ensino fundamental, pessoas portadoras de deficiência e autodeclarados indígenas e negros. Baseia-se no modelo objetivo, cujo o principal intuito é o de caracterizar os aspectos da eficiência, efetividade e impacto, a partir da interpretação dos resultados alcançados.

A Lei 11.096/2005 prevê que um percentual de bolsas de estudos deve ser destinado a implantação de políticas afirmativas de acesso ao ensino superior de portadores de deficiência e autodeclarados negros e índios. Esse percentual é diferente nos diversos Estados da federação e o cálculo é feito com base no censo populacional da Fundação Instituto Brasileiro de Geografia e Estatística - IBGE. A taxa de autodeclarados índios ou negros varia de acordo com a formação étnica das regiões do país. Nos Estados do sul a porcentagem é menor que no sudeste, norte e nordeste. Mesmo com destinação de vagas aos autodeclarados negros e índios, os números do PORUNI demonstram que as pessoas de cor branca ou parda ocupam 763.042 vagas para um total cumulativo de bolsas do Prouni de 919.551 no ano de 2011. No ano 2009, os dados do Censo/Inep mostravam a existência de 5.080.056 alunos matriculados na Educação Superior, isto corresponde a 18\% da população amostral voltadas para as bolsas concedidas pelo Prouni.

Comparando-se aos sistemas internacionais, no caso brasileiro não existem avaliações de âmbito nacional destinadas a demonstrar o desempenho específico dos alunos beneficiários do PROUNI, nem dados que relatem alterações no desempenho do sistema como um todo, depois da implantação do programa que beneficia mais de $18 \%$ dos alunos do ensino superior.

A liberação de bolsas para os professores da educação básica em exercício na rede 
pública de ensino, não se submete aos mesmos critérios de aprovação aos quais estão submetidos os demais candidatos. A Lei 11.096/2005 prevê em seu artigo $2^{\circ}$, inciso III, que os professores da rede pública de ensino, para os cursos de licenciatura, normal superior e pedagogia, destinados à formação do magistério da educação básica, têm direito à bolsa de estudo, independente da renda familiar. Isso parece não ter se constituído num incentivo de fato, pois o total de professores bolsistas atinge apenas 8.818, num universo de 919.551 beneficiados (Fonte: Sisprouni 17/06/2011 - Prouni 2005-2\%/2011).

Os objetivos do programa PROUNI têm sido atingidos. Porém, não é seguro fazer referência aos gastos públicos para sustentar o Programa, sem a divulgação dos dados pelo Ministério da educação sobre o montante deixado de arrecadar pelas instituições em troca da disponibilização das bolsas, mas os indícios, com base com montante de alunos bolsistas, indicam que o programa tem beneficiado uma grande parcela dos estudantes de baixa renda. Contudo, existe necessidade de maior controle para evitar fraudes que beneficiam estudantes que não se enquadram nos critérios, corrigir as distorções nos números de bolsistas, sobretudo das maiores instituições que recebem grandes somas de isenção em troca de pequenas quantidades de bolsas e a elaboração de pesquisas, pelos órgãos gestores do programa, para demonstrar as efetivas mudanças nas condições socioeconômicas dos beneficiados e de suas famílias.

O programa Prouni, em termos quantitativos, atinge o objetivo pretendido com eficácia, porém qualitativamente, não se pôde avaliar até a presente data, por não adotar um sistema de avaliação nacional do desempenho dos alunos. É um programa jovem com apenas 07 (sete) anos de existência e tem demonstrado fragilidade com relação ao controle, organização e qualidade sistêmica e estrutural. Precisa ser analisado, avaliado e desenvolvido para que as discrepâncias detectadas sejam corrigidas e preventivamente medidas sejam tomadas para que as brechas sejam tapadas. Evitando assim falhas que beneficiem negativamente os aproveitadores.

Uma das questões polêmicas na área da educação e que se encontra presente na Constituição Federal (CF) de 1988 é o princípio educacional da gestão democrática. Contraditoriamente, é o único princípio constante da área educacional que teve sua abrangência limitada ao âmbito público, pois, nos termos do artigo 206, item VI, a gestão democrática ficou restrita ao "ensino público, na forma da lei”.

Esta limitação, que poderia ser entendida como "distração", pelo caráter democratizante da Constituição, com claro incentivo à participação popular, representou, na verdade, um embate político em que o pensamento pedagógico conservador e privatista 
foi vitorioso. E esta circunscrição da gestão democrática escolar e educacional terá consequências mais extensas e permanentes do que se considerou inicialmente.

Mesmo estando garantidos os direitos de "ensinar e aprender", a partir do reconhecimento da necessária autonomia da prática docente e "do pluralismo de ideias e de concepções pedagógicas" (art. 206, itens II e III), estes direitos, na década seguinte à da promulgação da Constituição, começam a ser interpretados como o direito dos sistemas escolares estabelecerem currículos e programas minuciosos para orientar a prática pedagógica, à luz do proposto nos Parâmetros Curriculares Nacionais (PCNs).

De certa maneira, o Estatuto da Criança e do Adolescente (ECA - Lei n. 8.069/90) parece ter previsto esta possibilidade, pois, ainda em 1990, definiu como direito dos pais direito este até hoje não respeitado ou implementado plenamente - a participação na definição das propostas pedagógicas das escolas de seus filhos, bem como ter conhecimento do processo pedagógico (art. 53, Parágrafo Único), acompanhando seu desenvolvimento e avaliação.

Também os alunos tiveram explicitado dois direitos que, à primeira vista, poderiam parecer dispensáveis, mas que a prática mostrou serem procedentes: primeiro, o direito de conhecer e contestar os critérios de avaliação da aprendizagem adotados por seus professores (art. 53, III - ECA); e, segundo, a obrigação do poder público estimular pesquisas, experiências e novas propostas educacionais, visando à inserção de crianças e adolescentes excluídos do ensino fundamental obrigatório (art. 57) e ao desenvolvimento pleno dos alunos que apresentem dificuldades de aprendizagem, fruto de suas condições de vida e do contexto social e cultural em que vivem, garantindo-se sua liberdade de criação e de acesso às fontes de cultura (art. 58 - ECA).

A Lei de Diretrizes e Bases da Educação Nacional (LDB - Lei n. 9.394/96), ainda que num só artigo, propõe uma participação de caráter mais coletivo no processo de elaboração e decisão do projeto pedagógico de cada escola, prevendo a participação das comunidades escolar e local em "conselhos" escolares ou equivalentes (art. 14). Ou seja, estabelece que o "sucesso" do processo e do projeto pedagógico é fruto de uma reflexão mais coletiva do que tradicionalmente se admitia, e que sua adequação aos interesses e necessidades dos diferentes grupos de alunos definirá a qualidade de ensino. Pode-se deduzir, nesta concepção, que a "qualidade" só é evidenciada na implementação desta inter-relação de fatores.

Por outro lado, a definição das políticas educacionais dos diferentes sistemas de ensino - federal, estaduais e municipais - também tem como pressuposto uma ação mais 
solidária entre as esferas públicas, uma vez que o sistema federativo implica colaboração e distribuição, a mais equitativa possível, de responsabilidades e tarefas entre elas.

Esta é a razão por que a elaboração de planos de educação, atualmente, e pelo menos no discurso e na legislação, deixou de ser atividade exclusiva de "especialistas" que, historicamente, manipulavam dados estatísticos e informações em seus gabinetes, para se tornar iniciativa democrática, em que os diferentes segmentos sociais são convidados a se pronunciar e a se envolver na definição de suas diretrizes e prioridades.

Outro problema detectado com relação a educação brasileira, segundo Melo (1999) e Arretche (2003), é de que a área de políticas públicas no Brasil se caracteriza por uma baixa capacidade de acumulação de conhecimento, em função da proliferação horizontal de estudos de caso e da ausência de pesquisa.

De cada 10 professores que dão aulas na educação básica brasileira, dois trabalham sem diploma de ensino superior. O índice de docentes não graduados é maior nas turmas da educação infantil, mas há professores trabalhando sem formação adequada inclusive no ensino médio.

Os números do Censo Escolar 2012 mostram que 22\% dos 2.101 .408 professores brasileiros - 459 mil - não chegaram à universidade. Desse total, 8.339 terminaram apenas o ensino fundamental, 115.456 concluíram o ensino médio regular e 335.418, o magistério. Entre os 1,6 milhão diplomados, 223.777 não cursaram licenciatura, modalidade que prepara professores.

É na educação infantil que trabalha grande parte dos professores sem formação superior. Dos 443,4 mil professores dessa etapa, 36,4\% não se graduaram. De acordo com a Lei de Diretrizes e Bases da Educação, é permitido que um professor que concluiu apenas o magistério lecione nessa fase, mas 10\% dos docentes sequer têm essa formação mínima.

Nos anos finais do ensino fundamental e no ensino médio, fases em que todos os professores, por lei, deveriam ter cursado licenciatura para dar aulas, o cenário se repete. Do $6^{\circ}$ ao $9^{\circ}$ ano do fundamental, $22 \%$ dos 801 mil educadores não têm formação adequada (não cursaram faculdade ou licenciatura). No ensino médio, 18\% dos 497 mil docentes estão nessa situação.

Para a ex-secretária de Educação Básica do Ministério da Educação e diretora da Fundação SM, Pilar Lacerda, todos os professores deveriam ser formados no ensino superior. "A profissão docente é muito complexa e requer formação específica e séria. A qualidade da educação está intimamente ligada à qualidade do profissional da educação. 
Aquela visão de que basta boa vontade e gostar de crianças está ultrapassada", afirma.

A formação dos professores brasileiros, de modo geral, melhora a cada ano. Em 2011, o número de educadores sem curso superior (530.029) representava um quarto do total. Apesar disso, as diferenças regionais ainda persistem. Grande parte dos docentes com formação precária atua no Nordeste. Quase metade dos educadores com apenas o diploma de ensino médio regular - 50 mil dos 115 mil do País - leciona nas salas de aula nordestinas.

A Bahia é um dos Estados com mais problemas de formação dos docentes. Dos 157 mil professores, 1.150 têm apenas o ensino fundamental (13,8\% de todos que estão nessa condição); 19 mil cursaram apenas o ensino médio regular e 50,8 mil não passaram do curso normal (magistério). Apenas a metade cursou uma faculdade.

Sem incentivos para atrair os melhores estudantes para a carreira, especialistas acreditam que será difícil superar os problemas de formação dos professores, que não se esgota apenas com o estímulo à graduação. Na opinião de Daniel Cara, coordenador da Campanha Nacional pelo Direito à Educação, há problemas estruturais de formação dos alunos que só são solucionados dentro dos cursos de graduação. "O aluno que não teve uma formação básica adequada não vai conseguir ser um bom professor. E, na média, infelizmente, são os alunos que tiveram mais dificuldades que acabam na profissão. A tendência do Brasil sempre é boa, mas temos um problema de ritmo dessa evolução na qualidade de ensino", pondera. Segundo ele, a aprovação do Plano Nacional da Educação é importante para garantir recursos que acelerem a formação dos professores.

Pilar defende melhores salários e uma perspectiva mais atraente de carreira para mudar o cenário da educação. "A profissão não pode ser escolhida enquanto o jovem não acha coisa melhor", comenta. Cara acredita que os cursos presenciais têm de expandir de forma mais direcionada, especialmente nas regiões em que eles são escassos.

Os dados do Censo Escolar mostram também que 1,6 milhão do total de professores do País é mulher. A região Nordeste é a que, proporcionalmente, possui mais educadores homens na educação básica. Dos 613 mil professores da região, 20\% são homens. Metade dos docentes tem entre 25 e 40 anos de idade.

Dos 2 milhões de docentes da educação básica, 443 mil dão aulas na educação infantil; 1,4 milhão no ensino fundamental, 497 mil no ensino médio e 253 mil na educação de jovens e adultos.

Diante do exposto, um efeito "cascata" desencadeado desde a educação básica tem afetado o ensino superior, formando profissionais que assumirão posições futuramente e 
que serão avaliados negativamente pela sociedade por seus serviços prestados. Criando-se assim um ciclo vicioso impossibilitando a oportunidade de melhoria com relação à qualidade na educação brasileira.

Portanto, nem sempre a aplicação quantitativa de esforços na educação garantem a excelência desejada. Isto demonstra que a qualidade na aplicação dos recursos na área da educação também não tem sido correspondidas. O desperdício, a falta de qualificação profissional, a falta de uma pesquisa mais acentuada e voltada para as necessidades internas de nosso país, deixando para um momento oportuno a aplicação das experiências internacionais, e utilizando-se como verdade absoluta as exigências impostas pelos Órgãos Internacionais, são fatores negativos visualizados na Gestão Pública atual.

Segundo Frey, "a fase da avaliação é imprescindível para o desenvolvimento e a adaptação contínua das formas e instrumentos de ação pública” (Frey, 2000:229).

Para tomarmos decisões corretas relacionadas a qualificar a educação implantando uma política pública adequada, recomenda-se parametrizar até onde queremos chegar e qual será o referencial para alcançar este objetivo. Definir se estamos lidando com números, pessoas ou os dois fatores simultaneamente. Não poderemos negar que outros fatores, principalmente o econômico, serão influenciados ou irão influenciar diante deste processo. Porém, uma nação onde seu futuro depende deste processo decisorial que será tomado pelas autoridades governamentais e que a população na verdade é quem deveria conduzilos como seu representante.

\section{3 - Considerações Finais}

Podemos considerar que com as pessoas certas nos lugares certos, bem qualificadas e treinadas, com uma adequação e implantação de políticas públicas voltadas para nossas demandas sem introduzir pacotes internacionais que não condizem com nossa realidade, com um Órgão fiscalizador externo, como exemplo o CGU, efetuando auditorias voltadas para a área da educação, dentro dos prazos necessários, com uma análise curricular mais específica do que generalista da formação de novos profissionais e tendo como base uma Instituição séria e impessoal voltada para o fornecimento na íntegra dos índices estatísticos supervenientes, há uma grande possibilidade de qualificarmos melhor a educação brasileira. 


\section{Notas}

1"Este artigo é um produto vinculado aos projetos "Corpo, Educação e Sociedade" e "Corpo, Gênero Educação" ambos apoiados pelo CNPQ".

${ }^{2}$ Uma versão preliminar deste trabalho foi apresentada no Seminário Internacional Inclusão em Educação: Universidade e Participação 3, ocorrido em maio de 2013, na UFRJ, Rio de Janeiro-RJ.

\section{Referências temáticas}

Brasil. Ministério da Educação. Programa Universidade para Todos. Disponível em www.mes.org.br Acesso em 17/03/2012

BULMETTIS, John. e DUTWIN, Phyllis. The ABCs of Evaluation. Jossey-Bass Publishers: San Francisco, 2000.

DERLIEN, H-U. Una comparación internacional en la evaluación de las políticas públicas. Revista de serviço público, 52 (1): 105-123.

COLLINS, Randall. Quatro tradições sociológicas. Petrópolis, RJ. Vozes. 2009.

CORNEJO, Rodrigo. El experimento educativo chileno 20 años después: una mirada crítica a los logros y falencias del sistema escolar. Revista Electrónica Iberoamericana sobre Calidad, Eficacia y Cambio en Educación, v.4, n. 1, 2006. 
DOURADO. Luiz Fernandes. Avaliação do Plano Nacional de Educação 2001-2009: questões estruturais e conjunturais de uma política. Educ. Soc., campinas, v. 31, n. 112, p. 677-705, jul.-set. 2010

FARIA, Carlos Aurélio Pimenta. A política da avaliação de políticas públicas. Revista Brasileira de Ciências Sociais. São Paulo, v. 20, n.59, out. 2005.

FARIA, Carlos Aurélio Pimenta; FLGUEIRAS, Cristina Almeida Cunha. As políticas dos sistemas de avaliação da Educação Básica. In: HOCHMAN, G; ARRETCHE, M.; 16

MARQUES, E. (orgs) Políticas Públicas no Brasil. Rio de Janeiro : FIOCRUZ, 2007, P. 327-367.

FARIA, Carlos Aurélio Pimenta de. A Política da Avaliação de Políticas Públicas. IN

Revista Brasileira de Ciências Sociais Volume $20 \quad \mathrm{n}^{\circ} \quad 59$. disponível em http://www.scielo.br/pdf/\%0D/rbcsoc/v20n59/a07v2059.pdf acessado em janeiro de 2011.

GUBA, E; LINCOLN, Y. Fourth generation evaluations. Nova York. Sage Publications. 1989.

HERMAN, J.L. et alii. Evaluator's Handbook. Sage Publications: Newbury Park, 1987.

HOLANDA, Antonio NILSON Craveiro. Avaliação de políticas públicas : conceitos básicos, o caso do ProInfo e a experiência brasileira. Trabalho apresentado no VIII Congreso Internacional del CLAD sobre la Reforma del Estado y de la Administración Pública, Panamá, 28-31 Oct. 2003. Disponível en: ttp://unpan1.un.org/intradoc/groups/public/documents/CLAD/clad0047614.pdf MACEDO SÁ, José Wilton Bessa. Modelo de Avaliação de Desempenho da Gestão Organizacional Pública. Dissertação de Mestrado. UEC, 2005.

MORDUCHOWICZ, Alejandro. El subsidio a la demanda: entre los límites de la economía 
y los (irresueltos) problemas educativos. Revista de Tecnologia Educativa, Universidad de San Buenaventura. Seccional Medellin, V.14. No.1/2, p.29-49, 2000.

OECD. Reviews of national policies for education: Chile. Paris: Organisation for Economic Cooperation and Development. 2004

SARAVIA, Enrique. FERRAREZI, Elisabete. (orgs.) Políticas públicas. V I. Brasília: ENAP, 2006.

SOUZA. Celina. Política públicas: uma revisão da literatura. Sociologias, Porto Alegre, n.16, jul.dez., 2006. Disponível em: www.scielo.com Acesso em 16/07/2008.

VIEIRA, Aline Rodrigues Mendes. Planejamento e Políticas Públicas de Turismo: análise dos módulos operacionais do Programa de Regionalização do Turismo no Pólo São Luis MA. Dissertação de Mestrado. Universidade de Brasília. 2011.

Weiss, Carol, 1998, Evaluation, 2. edition, Prentice-Hall, New Jersey.

WORTHEN, Blaine R., SANDERS, James R., FITZPATRICK, Jody L. Program Evaluation, Alternative Approaches and Practical Guidelines, Addison Wesley Longman, New York, 1997.

BRASIL. Emenda Constitucional n. 14, de 12 de setembro de 1996. Modifica os art. 34, 208, 211 e 212 da Constituição Federal e dá nova redação ao art. 60 do Ato das Disposições Constitucionais Transitórias.

Diário Oficial da União, Brasília, DF, 13 set. 1996.

BRASIL. Emenda Constitucional n.19, de 4 de junho de 1998. Modifica o regime e dispõe sobre princípios e normas da Administração Pública, servidores e agentes políticos, controle de despesas e finanças públicas e custeio de atividades a cargo do Distrito Federal, e dá outras providências.

Diário Oficial da União, Brasília, DF, 5 jun. 1998.

BRASIL. Lei n. 5.692, de 11 de agosto de 1971. Estabelece as Diretrizes e Bases da 
Educação Nacional. Brasília, DF: MEC, 1972.

BRASIL. Lei n. 8.069, de 13 de julho de 1990. Dispõe sobre o Estatuto da Criança e do Adolescente. Diário Oficial da União, Brasília, DF, 16 jul. 1990. Disponível em: $<$ http://www.mec.gov.br/secad. $>$

Acesso em: 20 ago. 2004.

BRASIL. Lei n. 9.394, de 20 de dezembro 1996. Estabelece as Diretrizes e Bases da Educação Nacional. Diário Oficial da União, Brasília, DF, 23 dez. 1996. p. 27894. Disponível em: <http://

www.mec.gov.br/legislacao> Acesso em: 23 mar. 2005.

BRASIL. Ministério da Educação. Instituto Nacional de Estudos e Pesquisas Educacionais (INEP). Sinopses estatísticas, 1996 e 2006. Disponível em $<$ http://www.mec.gov.br/inep/estatisticas $>$. Acesso em: 15 jul. 2007

COSTA, V.L.C. (Org.). Descentralização da educação: novas formas de coordenação e financiamento. São Paulo: Cortez; FUNDAP, 1999.

FERREIRA, F.W. Planejamento: sim e não. 2. ed. Rio de Janeiro: Paz \& Terra, 1981.

FREIRE, P. A educação na cidade. São Paulo: Cortez, 1991.

FOLHA de S. Paulo, São Paulo, 30 jan. 2006. Caderno Cotidiano, p. 3 .

FOLHA de S. Paulo, São Paulo, 17 abr. 2007. Caderno Cotidiano,p. 5.

Educ. Soc., Campinas, vol. 28, n. 100 - Especial, p. 899-919, out. 2007919 Disponível em $<$ http://www.cedes.unicamp.br> Lisete R. G. Arelaro

HARVEY, D. Condição pós-moderna. 4. ed. São Paulo: Loyola, 1989.

HOBSBAWM, E. A era dos extremos: o breve século XX (1914 -1991). São Paulo: Cia das 
Letras, 1995.

PARO, V.H. Administração escolar: introdução crítica. 13. ed. São Paulo: Cortez, 2005.

PONTUAL, P. Construindo uma pedagogia democrática de poder. Polis, São Paulo, n. 15, p. 25-35, 1995.

SILVA, L.H. (Org.). A escola cidadã no contexto da globalização. Petrópolis: Vozes, 1998.

FERREIRA, Aurélio Buarque de Holanda. Dicionário Aurélio Eletrônico: século XXI. Rio de Janeiro: Nova Fronteira, 1999. versão 3.0. CD-ROM.

FREY, Klaus. Políticas públicas: um debate conceitual e reflexões referentes à prática da análise de políticas públicas no Brasil. Planejamento e Políticas Públicas, Brasília, n. 21, p. 211 259, jun. 2000.

CARVALHO, Sonia Nahas de. Avaliação de programas sociais: balanço das experiências e contribuição para o debate. São Paulo em Perspectiva, São Paulo, v. 17, n. 3-4, p. 185-197, jul./dez. 2003.

COSTA, Frederico Lustosa da; CASTANHAR, José Cezar. Avaliação de programas públicos: desafios conceituais e metodológicos. Revista de Administração Pública, Rio de Janeiro, v. 37, n. 5, p. 962-969, set./out. 2003.

COT'TA, Tereza Cristina. Avaliação educacional e políticas públicas: a experiência do Sistema Nacional de Avaliação da Educação Básica (Saeb). Revista do Serviço Público, Brasília, v. 52 , n. 4 , p. $89-110$, out./dez. 2001.

Priscilla Borges - iG Brasília, 05/04/2013.

AZANHA, J. Mário Pires. Educação: temas polêmicos. São Paulo: Martins Fontes, 1995.

AGUILAR, Luis Enrique. Estado desertor: Brasil-Argentina nos anos de 1982-1992. Campinas, SP.: FE/UNICAMP; R. Vieira, 2000. 
APEOESP. Revista de Educação: progressão continuada ou aprovação automática. São Paulo: 2001, no 13.

POLÍTICAS PÚBLICAS EDUCACIONAIS: a importância do controle e da avaliação para obtenção dos resultados pretendidos, Hugo Costa Pessoa, Auditor do Tribunal de Contas; Mestre em Gestão de Políticas Públicas/UNIVALI/SC.

SHIROMA, E.; MORAES, M.C.; EVANGELISTA, O., Política educacional. 2ª ed. Rio de Janeiro: DP\&A, 2002. 